\title{
Assessing the test-retest reliability of career path appreciation as a measure of current and potential work decision-making capability
}

\author{
Authors: \\ Rudolf M. Oosthuizen ${ }^{1}$ \\ Melinde Coetzee ${ }^{1}$ \\ Ester Kruger $^{1}$ \\ Affiliations: \\ ${ }^{1}$ Department of Industrial \\ and Organisational \\ Psychology, University of \\ South Africa, South Africa \\ Correspondence to: \\ Rudolf Oosthuizen \\ Email: \\ oosthrm@unisa.ac.za \\ Postal address: \\ PO Box 392, UNISA 0003, \\ South Africa \\ Dates: \\ Received: 21 Feb. 2014 \\ Accepted: 07 May 2014 \\ Published: 21 Aug. 2014 \\ How to cite this article: \\ Oosthuizen, R.M., Coetzee, \\ M., \& Kruger, E. (2014). \\ Assessing the test-retest \\ reliability of career path \\ appreciation as a measure \\ of current and potential \\ work decision-making \\ capability. SA Journal of \\ Industrial Psychology, 40(2), \\ Art. \#1199, 8 pages. http:// \\ dx.doi.org/10.4102/sajip. \\ v40i2.1199

\section{Copyright:} \\ C 2014. The Authors. \\ Licensee: AOSIS \\ OpenJournals. This work \\ is licensed under the \\ Creative Commons \\ Attribution License.
}

Orientation: Assessing and developing managerial decision-making capability in a complex and volatile marketplace is imperative for most South African businesses.

Purpose: The objective of this study was to assess the test-retest reliability of the career path appreciation (CPA) procedure in assessing current and potential levels of work decisionmaking capability. The study also explored whether different gender and race groups differed significantly in terms of these levels at two CPA assessments.

Motivation for the study: Limited recent test-retest research has been done regarding the reliability of the CPA technique as a tool for measuring the work decision-making capability of professional and managerial talent in the South African context. Scholars and practitioners in the field of industrial psychology could therefore benefit from follow-up research into the reliability of CPA.

Research approach, design and method: The research followed an ex post facto correlational design using longitudinal data of a non-probability purposive sample $(N=527)$ within the Bioss SA database.

Main findings: The results showed that the participants' first CPA assessment scores correlated significantly and positively with their second CPA assessment scores. Gender and race groups differed significantly in their levels of current work decision-making capability at both assessments.

Practical/managerial implications: The CPA procedure can be used with confidence as an assessment tool in the selection, mentoring and development of high-potential managerial and professional talent for diverse gender and race groups.

Contribution/value-add: These findings contribute valuable information regarding the reliability of CPA and the differences between race and gender groups in the South African context.

\section{Introduction}

Assessing and developing managerial decision-making capability in an increasingly complex and volatile business marketplace has become imperative for most South African businesses (Comaroff, 2012; Kruger, 2013). Organisations increasingly recognise the importance of acquiring and developing managerial talent as represented by staff who are able to cope with the cognitive complexities required for effective decision-making in a continuously changing environment (Comaroff, 2012). Apart from the organisation's demand for growth in human capabilities, individuals too must rely more heavily on their own decision-making capabilities to navigate their careers in an environment in which career paths have become blurred and uncertain (Converse, Pathak, DePaul-Haddock, Gotlib \& Merbedone, 2012). This study focuses on the reliability of the career path appreciation (CPA) technique as a tool for measuring the current and potential future work decision-making capability of managerial and professional talent in the multicultural and gender-diverse South African context.

In the context of the study, work decision-making capability refers to an individual's ability to cope with the cognitive complexity required for effective decision-making in complex environments (Comaroff, 2012; Kitching, 2005). The CPA technique is a well-established measure of work decision-making capability (Comaroff, 2012; Kitching, 2005; Mauer, 2000; Stamp \& Stamp, 1993). CPA enables management to form a view, with the respondent, about their potential to deal with complexity and to make judgements that add value to a particular level of work complexity (Kitching, 2005). Research provides evidence that this capability can 
develop with age and can be forecast or predicted with encouraging levels of accuracy (Lewis, 1993; Stamp, 1989).

The CPA measure is used in the recruitment, mentoring and development of people in a variety of organisations and industries locally and internationally (Comaroff, 2012; Kitching, 2005). In South Africa, approximately 3500 CPAs are conducted annually on average. The CPA procedure is utilised to assist in the identification of potential talent at an early stage and to help organisations to fast-track and develop talent for the future (Kruger, 2013). CPA provides results indicating the probable rate of growth of current levels of work decision-making capability in individuals and their organisations. The instrument can therefore assist individuals in making more informed career-related decisions, in pacing themselves in their career growth and in preparing for additional responsibilities (Stamp, 1989). This makes CPA a tool that enables organisations to find and utilise resources optimally within their organisational context (Kruger, 2013).

\section{Research purpose and objectives}

The objective of the study was to assess the test-retest reliability of the CPA procedure in assessing current and potential level of growth in work decision-making capability. The study also explored whether people of different genders and races differed significantly in terms of their levels of work decision-making capability at their first and second CPA assessments.

\section{The potential value-add of the study}

CPA is regarded as a costly assessment tool (Comaroff, 2012) because it consists of a one-on-one interview and requires a highly trained and skilled practitioner (Stamp, 1989). In South Africa, the cost of training CPA practitioners as well as the shortage of skilled CPA practitioners adds to the expense of implementing this assessment technique (Comaroff, 2012). Confirming its reliability is therefore imperative if it is to be used in managerial and professional talent assessment and development (Kruger, 2013). Although CPA is renowned for its sound psychometric and cultural-unbiased and gender-unbiased properties (Kitching, 2005; Mauer, 2002, 2005), limited recent testretest research has been done regarding the utilisation of CPA in the diverse and multicultural South African context. In South Africa specifically, the use of assessments to make decisions regarding the employability of an individual is continuously scrutinised (Mauer, 2008); the Labour Relations Act, enacted in 1995, is intended to ensure that organisational employment practices are fair, with specific, job-related and objective criteria against which individuals are measured to assess their employability. The Employment Equity Act of 1998 further states that the use of selection instruments is prohibited, unless the user can demonstrate that the instrument used is valid, reliable and fair (Nzama, De Beer \& Visser, 2008). Research on gender and race groups in relation to CPA is inconclusive
(Kitching, 2005). By investigating whether gender and race groups differ in terms of their level of work decision-making capability will therefore further contribute to the research literature on the CPA measure. Scholars and practitioners in the field of industrial psychology could therefore benefit from continued follow-up research regarding the reliability of CPA and in particular its application in terms of race and gender groups in the South African employment equity context (Mauer, 2008).

\section{Literature review}

CPA, developed by Gillian Stamp (1988), is a multifaceted complex interview-based assessment technique designed to measure an individual's current and probable future capability for making effective decisions and meeting the conceptual demands of various work roles (Kitching, 2005; Lewis, 1993). As a measure of work decision-making capability, CPA differs from traditional approaches in that it is based on the operationalisation of stratified systems theory and does not rely on classical test theory (Mauer, 2008). The CPA procedure focuses on the relationship between capabilities and challenges in the context of both the individual and the organisation.

CPA is administered by means of a systematic appreciative interview in which lived experience is probed and through which a practitioner comes to an understanding of the capability an individual is comfortable applying at any given stage in their career path. The interview-based procedure aims to balance both the capabilities and careers of employees with the needs of the organisation so that there is a mutual benefit for both parties (Comaroff, 2012; Kitching, 2005; Stamp, 1989). The term 'appreciation' is indicative of the mutual respect between employee and employer: both parties recognise the current scope of a person's ability to make decisions, the probable rate at which that ability will grow and the steps that could ensure the realisation of that potential (Stamp, 1989). To achieve this level of appreciation, the CPA interview involves inter alia the use of phrase cards designed to guide the conversation in terms of the respondent's approach to the work in which they are currently involved. The procedure further involves the sorting of symbol cards of different shapes, colours, sizes and so on according to a predetermined rule unknown to the respondent. The sorting facet offers insight into a respondent's ability to create order out of disorder. The third facet involves a discussion with the respondent about their current work, the history of their career and their future career aspirations. Emphasis is placed on times when the respondent has felt at ease, overstretched or underused with regard to their responsibilities (Ashton \& Kruger, 2008). The CPA process allows a trained practitioner to observe how discretion is exercised and how the respondent copes with complexity (Kitching, 2005).

The theoretical framework of the CPA procedure is based on two key concepts contained in the stratified systems theory of Elliott Jaques $(1978,1990)$. The first is the notion 
that work is hierarchically stratified such that higher-level managerial positions entail dealing with greater complexity than do lower-level positions (Lewis, 1993). Jaques (1990) views work as the exercise of discretion and judgement in decision-making in carrying out tasks. Work is seen to be driven by values and to bring skilled knowledge into play. Work not only becomes more complex, but it can also be separated into distinct categories of complexity based on the interplay between discretion, judgement and experience (Jaques \& Cason, 1994).

The second key concept relates to the idea that there are qualitatively distinct levels of individual conceptual capability that correspond to levels of work complexity (Jaques, 1990, 1996; Jaques \& Clement, 1994; Lewis, 1993). CPA was designed to assess these levels of individual capability (Lewis, 1993). Capability, as conceptualised in terms of stratified systems theory, refers to the decisionmaking process in the face of uncertainty (Ashton, Calitz \& Solms, 2009) and the individual's ability to deal with complexity. Capability involves individuals' 'take' on a situation or how they scan and read a setting or context (termed sunesis), as well as an element of how people exercise their judgement in a particular situation (termed phronesis). It also involves the way people's decisionmaking capability grows or unfolds over time (Ashton \& Kruger, 2008).

CPA focuses on three main aspects of career pathing, namely (1) locating an individual's current age and current level of work decision-making capability; (2) understanding where the individual's potential future work decisionmaking capability (termed mode) lies in accordance with growth curves postulated by Jaques $(1990,1996)$ and (3) the individual's approach to work or work style (Stamp, 1989). An extensive study of earnings and management progression by Jaques $(1972,1978)$ shows that an increase in earnings could be closely related to an increase in capability, which he terms 'growth curves'. Jaques (1990, 1996) subsequently developed the hypothesis that these curves might also represent growth in the capability of individuals to utilise their discretion at wider and more complex levels of work (Ashton \& Kruger, 2008). Jaques (1990, 1996) postulates stages of maturation along particular levels of complexity that require a matching level of cognitive power, regardless of the age at which the individual reaches that level. He further postulates certain differences in the different growth bands along which individuals mature, each of which is associated with a different growth rate and potential achievable level (termed mode). Jaques recognises a maximum level of complexity that any person can cope with at a particular point in their development, which is dependent on the level of cognitive information processing of which that person is capable (Jaques \& Clement, 1994).

Longitudinal research provides evidence that the postulated career path derived from a CPA assessment gives an accurate prediction of the probable rate of growth in increasing degrees of complexity that an individual will be comfortable with throughout their career (Mauer, 2000, 2005; Stamp, 1981). CPA theory postulates that as individuals mature (age) within their jobs and are required to take on more challenging tasks, they are able to deal with higher levels of work complexity (Comaroff, 2012). The growth curves show an individual's current and potential future work decision-making capability based on their chronological age maturation or capabilities over time (Stamp \& Stamp, 1993). The CPA procedure therefore takes the respondent's age into consideration because age is seen to influence the prediction of the respondent's growth processes (Comaroff, 2012).

Growth curves are grouped into development curves indicating an active link between individual decisionmaking capability and the organisational level of work requirement, as well as the maximum point of development (potential capability or mode) in the corresponding level of work (Stamp, 1988). Matching individual growth in capability with the corresponding level of work is critical in maximising individual decision-making capability and inducing a state of flow (Csíkszentmihályi, 1975, 2003). People experience growth towards complexity with increased experiences of flow (Csíkszentmihályi, 2003).

In terms of gender and race, Mauer (1997) and Percival, Crous and Schepers (2003) found no significant differences between men and women and different race groups in terms of their CPA scores. However, research on differences between gender and race groups in terms of their CPA outcomes is sparse and needs further investigation (Kitching, 2005). The career literature provides evidence that men and women have different chronological age-related psychological career attitudes, which may influence their career decision-making capability (O'Neil \& Bilimoria, 2005; Schreuder \& Coetzee, 2011; Super, 1990). Similarly, the historically White male-dominant organisational cultures of Western society and affirmative action legislation tend to influence people's career decision-making attitudes and capabilities (Schreuder \& Coetzee, 2011). Research by Harry (2014) also shows that men and women and different race groups differ in terms of their career capabilities.

\section{Research design Research approach}

The research took the form of an ex post facto quantitative study that used two waves of archival data from a non-probability purposive sample. The study is original in that it correlated information on the participants' current and potential level of work decision-making capability (as assessed by the CPA procedure at a certain point in their careers) with their level of current and potential work decision-making capability four years later. This research approach enabled the researchers to assess the testretest reliability of the CPA procedure in assessing work decision-making capability. 


\section{Research method}

\section{Research participants}

The sample was a non-probability purposive sample of 527 participants whose CPA data was archived on the Bioss SA Genie database. Of the participants, $46 \%$ were white, $44 \%$ black, $7 \%$ Asian and 3\% mixed race. The sample comprised predominantly men (84\%). The participants occupied skilled $(53 \%)$ and managerial $(47 \%)$ positions at the time of their first and second CPA assessments. In terms of chronological age, Table 1 shows that the participants were between the ages of 28 and 40 years (mean age $=33.84 ; \mathrm{SD}=6.48$ ) at their first $\mathrm{CPA}$ assessment and between 32 and 44 years (mean age $=37.76$; $\mathrm{SD}=6.88)$ at their second CPA assessment. The skewness and kurtosis indicates a normal distribution of age at the first and second CPA assessments. The average difference in years between the first and second CPA assessments was 3.9 years, implying that the participants were within a particular decision-making capability growth curve at the time of both CPA assessments (Kruger, 2013; Stamp, 1988). This warranted a more reliable assessment of the test-retest reliability of the first and second CPA assessments.

\section{Measuring instrument}

Level of current and potential future work decision-making capability was measured by means of the well-researched CPA procedure developed by Stamp (Percival et al., 2003; Stamp, 1988, 1989). Although the CPA assesses three aspects of career pathing, namely current level of capability, potential level of capability and work style, the present research focused only on the capability and mode aspects of the CPA procedure. The CPA procedure constitutes a complex oneto-one semi-structured interview lasting approximately two to four hours that links the scope of a person's capacity to exercise judgement with the organisational requirement to do work at a particular level of complexity (Lewis, 1993). The CPA takes a holistic view of the basic cognitive capability of an individual to operate at a certain level of complexity rather than in a specific position (Stamp, 1981). Taking the form of a 'guided conversation' in four phases (nine sets of phrase cards, a symbol card task, a career history interview and feedback), it is a procedure for exploring and understanding the relationship between people and their working life (Ashton \& Kruger, 2008). CPA results take the form of an overall score of current level of work decisionmaking capability as well as a projected score for 5, 10, and 15 years, hence of the individual's highest predicted future level of work decision-making capability according to empirically derived progression or potential growth curves, termed 'mode' by Jaques (1996). The predictions of capability are made on the basis of the initially assessed capability and chronological age (Percival et al., 2003).

The CPA procedure is conducted by a highly trained practitioner and standardised scoring procedures are used (Ashton \& Kruger, 2008; Lewis, 1993). CPA scores are derived from a very complex scoring process in which the scorer (trained practitioner) makes judgements concerning level of capability based on both the form and the substance of the subject's performance in a number of tasks (Lewis, 1993). Research indicates acceptable levels of inter-rater reliability with correlation coefficients ranging between 0.71 and 0.95 (Kitching, 2005; Mauer, 2005). Inter-rater mean absolute agreements range between $90 \%$ and 100\% (Kitching, 2005). Research also provides evidence of the face validity, predictive validity, content validity as well as the construct validity of the CPA procedure (Mauer, 2000). Research by Kitching (2005) has confirmed the measurement outcome equivalence of the CPA procedure for groups of diverse cultural backgrounds in the South African context.

\section{Research procedure and ethical considerations}

The participants' data was extracted from the Bioss SA Genie database, which houses the data of the entire population of CPAs that have been completed internationally, for the following variables: date of birth, dates of the first and second CPA assessments, chronological age at the first and second CPA assessments, current level of work decision-making capability scores at the first and second CPA assessments, mode (potential future level of work decision-making capability) scores at the first and second CPA assessments, practitioner at the first and second CPA assessments, job category at the first and second CPA assessments, race and gender. Only participants with two CPA assessment scores obtained at different times by different practitioners were used to achieve the objective of the study. In the study, the notation CPA1 represents the first CPA assessment of a participant conducted by a particular practitioner and CPA2 represents the second CPA assessment conducted at a later date (approximately four years later) by a different practitioner.

In terms of ethical considerations, permission to use the archival data for research purposes was obtained from Bioss SA. Ethical clearance was obtained from the research institution. The participants signed a consent form that granted Bioss SA permission to enter the data into the Genie database and to use the data (anonymously) for research purposes. Confidentiality was maintained by the researchers.

TABLE 1: Age of participants at the time of the first and second Career Path Appreciation assessments.

\begin{tabular}{|c|c|c|c|c|c|c|}
\hline Variables & Mean & Median & Variance & SD & Skewness & Kurtosis \\
\hline Age at CPA1 & 33.84 & 33.02 & 42.04 & 6.48 & 0.56 & -0.13 \\
\hline Age at CPA2 & 37.76 & 36.91 & 47.35 & 6.88 & 0.43 & -0.34 \\
\hline Age differences between CPA1 and CPA2 & 3.91 & 3.47 & 7.09 & 2.66 & 0.95 & 1.21 \\
\hline
\end{tabular}




\section{Statistical analysis}

SPSS Statistics for Windows was used to analyse the data. The statistical analysis involved descriptive statistics and Pearson product-moment correlations in order to assess the correlations between the participants' first and second CPA assessment scores. Reliability is estimated by computing a correlation between two sets of measures that measure the same thing in the same sample of respondents in the same way (Guion \& Highhouse, 2006). In the research reported on, two waves of data were used, namely the scores obtained from the CPA procedure applied at two different points in time by different practitioners in order to assess the test-retest reliability of the CPA procedure. Test-retest reliability is an estimate of reliability obtained by administering the same form of a measurement procedure (e.g. the CPA procedure) to the same group of respondents on two different occasions, with a minimum time interval of six months between the two measurement applications (Cascio \& Aguinis, 2014). The time interval between the two CPA assessments was approximately four years and fell within a specific CPA growth curve (Jaques, 1996), which warranted test-retest reliability.

One-way analysis of variance was performed in order to test for significant mean differences between the gender and race groups for both CPA assessments. In order to counter the probability of a type I error, the significance value was set at the $95 \%$ confidence interval level $(p \leq 0.05)$.

\section{Results}

Table 2 reports the means and standard deviations obtained on the CPA assessments after the deletion of extreme values. The skewness values indicate a normal distribution of the scores obtained for both CPA assessments. As expected, the participants obtained slightly higher mean scores on the second CPA assessment for both their current level of work decision-making capability (CLC) and mode (highest predicted future work capability): CPA1 CLC mean $=3.55$ versus $\mathrm{CPA} 2 \mathrm{CLC}$ mean $=3.61$; $\mathrm{CPA} 1$ mode mean $=4.28$ versus CPA2 mode mean $=4.38$. As noted with regard to the increase in the chronological age of the participants, the minimal increase in mean scores between the first and second CPA assessments suggests that they were functioning cognitively within a particular decision-making capability growth curve at the time of the two CPA assessments. This warranted assessing the test-retest reliability of the CPA procedure in a reliable manner.

Correlations: Table 3 shows that in terms of the first CPA assessment, the participants' current level of work decision- making capability (CPA1 CLC) scores correlated significantly and positively ( $r=0.83 ; p \leq 0.001$; large practical effect) with their predicted potential level of work decision-making capability (CPA1 mode) scores. Similarly, in terms of the second CPA assessment, the participants' current level of work decision-making capability (CPA2 CLC) scores correlated significantly and positively $(r=0.83 ; p \leq 0.001$; large practical effect) with their predicted potential level of work decision-making capability (CPA2 mode) scores.

The participants' first CPA assessment's current level of work decision-making capability (CPA1 CLC) scores also correlated significantly and positively $(r=0.67 ; p \leq 0.001$; large practical effect) with their second CPA assessment's current level of work decision-making capability (CPA2 CLC) scores. Their current level of work decision-making capability (CPA1 CLC) scores also correlated significantly and positively $(r=0.48$; $p \leq 0.001$; moderate practical effect) with their second CPA assessment's predicted potential level of work decisionmaking capability (CPA2 mode) scores. Similarly, the participants' second CPA assessment scores for their current level of work decision-making capability (CPA2 CLC) also correlated significantly and positively $(r=0.48 ; p \leq 0.001$; moderate practical effect) with the predicted potential level of work decision-making capability scores they obtained in their first CPA assessment (CPA1 mode).

The scores obtained for the participants' first CPA assessment's predicted potential level of work decisionmaking capability (CPA1 mode) also correlated positively and significantly $(r=0.59 ; p \leq 0.001$; large practical effect) with the scores obtained for their second CPA assessment's predicted potential level of work decision-making capability (CPA2 mode).

Test for significant mean differences: Table 4 shows that the male participants obtained significantly higher mean

TABLE 3: Results of Pearson product-moment correlations for the first and second Career Path Appreciation assessments.

\begin{tabular}{lllll}
\hline Variables & $\begin{array}{l}\text { CPA1 } \\
\text { CLC }\end{array}$ & $\begin{array}{l}\text { CPA 2 } \\
\text { CLC }\end{array}$ & $\begin{array}{l}\text { CPA1 } \\
\text { mode }\end{array}$ & $\begin{array}{l}\text { CPA2 } \\
\text { mode }\end{array}$ \\
\hline CPA1 CLC & - & - & - & - \\
CPA2 CLC & $0.67^{*}$ & - & - & - \\
CPA1 mode & $0.83^{*}$ & $0.48^{*}$ & - & - \\
CPA2 mode & $0.48^{*}$ & $0.83^{*}$ & $0.59^{*}$ & - \\
\hline
\end{tabular}

$N=527$.

CPA1, First Career Path Appreciation assessment.

CPA2, Second Career Path Appreciation assessment.

CLC: Current level of work decision-making capability.

*, Significance: $p \leq 0.001$.

TABLE 2: Descriptive statistics.

\begin{tabular}{lllll}
\hline Variables & Minimum & Maximum & Mean & Skewness \\
\hline CPA1 CLC & 1.75 & 5.50 & 3.55 & 0.61 \\
CPA2 CLC & 1.75 & 5.50 & 3.61 & 0.20 \\
CPA1 mode & 2.50 & 6.75 & 4.28 & 0.16 \\
CPA2 mode & 2.25 & 6.75 & 4.38 & 0.81 \\
\hline
\end{tabular}


scores $(\mathrm{CPA} 1$ mean $=3.59 ; \mathrm{CPA} 2$ mean $=3.62 ;$ small practical effect) than the female participants (CPA1 mean $=3.41$; CPA2 mean $=3.47$; small practical effect) for their current level of work decision-making capability at both their first CPA $\left(F_{1,519}=6.08 ; p=0.01\right)$ and second CPA $\left(F_{1,519}=4.12 ; p=0.04\right)$ assessments. The male and female participants did not differ significantly in terms of their scores for their potential level of work decision-making capability (mode) at both their first and second CPA assessments.

Table 5 shows that, similar to the gender groups, the race groups differed significantly only in terms of the scores obtained for their current level of work decision-making capability for both CPA assessments. The White participants obtained significantly higher mean scores (CPA1 mean = 3.64; $\mathrm{CPA} 2$ mean $=3.72$; small practical effect) than the other race groups for their current level of work decision-making capability at both their first $\left(F_{4,399}=3.03 ; p=0.01\right)$ and second $\left(F_{4,399}=4.30 ; p=0.002\right)$ CPA assessments.

\section{Discussion}

\section{Outline of the results}

The objective of the research reported on was to assess the test-retest reliability of the CPA procedure in predicting potential growth in work decision-making capability. Overall, the results showed that the participants' first CPA assessment scores correlated significantly and positively with their second CPA assessment scores, even when the assessment was administered by different practitioners, after a time interval of approximately four years. These findings corroborate previous research on the reliability of the CPA procedure. Mauer $(2002,2005)$ also found that individuals' first CPA assessment results are accurately verified by the results of their second CPA assessments; this could be attributed to the standardised interviewing and scoring procedures used by well-trained CPA practitioners (Ashton \& Kruger, 2008; Lewis, 1993; Mauer, 2005; Percival et al., 2003; Stamp, 1988, 1993). The test-retest reliability of the CPA procedure for the particular group of participants could also be attributed to the fact that they were, after four years (at the time of their second CPA assessment), still employed in the same position (i.e. functioning at the same level of work complexity, responsibility and accountability). The mean scores obtained for the first and second CPA assessments were relatively close, implying, as posited by Stamp (1988), an active link between the individual theoretical level of work

TABLE 4: Results of analysis of variance: Significant mean differences for gender groups.

\begin{tabular}{|c|c|c|c|c|}
\hline \multirow[t]{2}{*}{ Variables } & \multicolumn{2}{|c|}{ Mean } & \multirow[t]{2}{*}{$F p$} & \multirow[t]{2}{*}{ Cohen $d$} \\
\hline & Male & Female & & \\
\hline CPA1 CLC & 3.59 & 3.41 & $6.08^{*}$ & 0.29 \\
\hline CPA1 mode & 4.31 & 4.30 & 0.01 & - \\
\hline CPA2 CLC & 3.62 & 3.47 & $4.12^{*}$ & 0.24 \\
\hline CPA2 mode & 4.37 & 4.38 & 0.02 & - \\
\hline
\end{tabular}

$N=527$.

CPA1: First Career Path Appreciation assessment.

CPA2: Second Career Path Appreciation assessment.

CLC: Current level of work decision-making capability.

${ }^{*}$,Significance: $\mathrm{F} p \leq 0.05$
TABLE 5: Results of analysis of variance: Significant mean differences for race groups.

\begin{tabular}{|c|c|c|c|c|c|c|}
\hline \multirow[t]{2}{*}{ Variables } & \multicolumn{4}{|c|}{ Mean } & \multirow[t]{2}{*}{$\mathrm{F} p$} & \multirow[t]{2}{*}{ Cohen $d$} \\
\hline & Asian & Black & $\begin{array}{c}\text { Mixed } \\
\text { race }\end{array}$ & White & & \\
\hline CPA1 CLC & 3.54 & 3.46 & 3.23 & 3.64 & 3.03* & 0.28 \\
\hline CPA1 mode & 4.24 & 4.32 & 4.10 & 4.32 & 0.69 & - \\
\hline CPA2 CLC & 3.56 & 3.48 & 3.43 & 3.72 & $4.30 *$ & 0.38 \\
\hline CPA2 mode & 4.41 & 4.33 & 4.43 & 4.45 & 1.12 & - \\
\hline
\end{tabular}

$N=527$.

CPA1: First Career Path Appreciation assessment.

CPA2: Second Career Path Appreciation assessment.

CLC: Current level of work decision-making capability.

*, Significance: $\mathrm{F} p \leq 0.05$.

decision-making capability and the organisational level of work requirement, as well as the maximum predicted point of potential development in the corresponding level of work. The participants were also, in terms of their chronological age, still functioning within the same decision-making capability development curve as assessed during their first CPA assessment. The classical work of Jaques (1972) and Stamp (1988) suggests that predicted future potential work decision-making capability increases and changes only as people mature (age) over time, with people demonstrating significantly higher levels of work decision-making capability and potential growth in capability at a higher level of work complexity, responsibility and accountability (Kruger, 2013). However, the study reported on here did not focus on maturation over time, but only on the test-retest reliability of the CPA procedure when applied to a group of people within a specific growth curve or maturation phase of their lives.

The study also explored whether gender and race groups differed significantly in terms of their current and predicted potential level of work decision-making capability at their first and second CPA assessments. The results showed that the male participants had significantly higher levels of current work decision-making capability than their female counterparts, as assessed at both their first and second CPA assessments. Work decision-making capability as measured by the CPA procedure relates to the decision-making process and the individual's ability to deal with complexity in the face of uncertainty (Ashton et al., 2009; Kruger, 2013). The observed differences in current level of work decisionmaking capability might be attributed to the participants' being in the establishment phase of their careers, as posited by Super (1990), and the notion that women tend to follow different career paths from men (O'Neil \& Bilimoria, 2005). Women in their mid-30s to late 40 s tend to be concerned with doing what has to be done in terms of their work and careers whilst simultaneously managing multiple relationships and responsibilities. During this phase of their careers they tend to experience less personal control and more dissatisfaction, especially with organisations and managers ( $\mathrm{O}^{\prime} \mathrm{Neil}$ \& Bilimoria, 2005). On the other hand, men tend to focus on dealing skilfully with the challenges and complexities of their careers, advancing in their careers, promotion, taking on additional responsibility and working towards marking their place in a chosen field of work (Schreuder \& Coetzee, 2011; 
Super, 1990). These psychological career-related attitudes could have influenced the CPA results of the participants.

The observed differences between the male and female participants are contrary to research conducted by Mauer (1997) and Percival et al. (2003), which indicated no differences between gender groups on CPA scores. The present study corroborated this by indicating that the male and female participants did not differ significantly in terms of their predicted potential growth in work decision-making capability (mode). According to O'Neil and Bilimoria (2005), women tend to move towards reinventing their contribution to their organisations, families and communities as they approach their 50s. Like men, who focus on holding, updating and innovating their reputation at work, they then start to view their careers as learning opportunities and a chance to make a difference to others (Schreuder \& Coetzee, 2011). This psychological career attitude could explain why the female participants showed a similar potential future growth in work decision-making capability to their male counterparts.

In terms of race, the results showed that the White participants had significantly higher levels of current work decisionmaking capability than the other race groups, as assessed at both their first and second CPA assessments. On the other hand, the various race groups did not differ significantly regarding their predicted potential growth in work decisionmaking capability (mode). These findings are contrary to previous research, which indicated no differences between the CPA scores of race groups (Kitching, 2005; Mauer, 1997; Percival et al., 2003). However, the observed differences between the race groups are in agreement with research conducted by Stamp and Retief (1996). The historically White and especially male dominated organisational culture trend could have attributed to the observed differences in current level of work decision-making capability between the White participants and other race groups.

\section{Practical implications}

The test-retest reliability of the CPA procedure confirms its usefulness in organisations and especially in the South African employment equity context. The CPA procedure can be used with confidence as an assessment tool in the selection, mentoring and development of high-potential managerial and professional talent. A CPA assessment might inform employees' current and future career development within the organisation and help to ensure a continued match between individual decision-making capability and work complexity which, in turn, could influence organisational performance (Ashton \& Kruger, 2010). Managers and industrial psychologists should also consider the work decision-making capabilities of gender and race groups and the factors that may potentially impede their current level of work capability. Increased organisational support in terms of facilitating individual potential decision-making capability in the case of diverse groups of employees is likely to result in an increase in both organisational and employee performance (Kitching, 2005; Kruger, 2013).

\section{Limitations and recommendations}

Some limitations of the research reported on here should be noted. The study was based on archival data. Although an advantage of archival data is that it is easy to obtain, cost effective and allows for large samples, it can nevertheless pose a number of challenges for the researchers using it. Firstly, researchers using the data have no control over how it was collected (Comaroff, 2012). In terms of the present study, the researchers had to rely on Bioss SA to collect and extract the data accurately. Secondly, as the CPA is used mainly for managerial and professional levels upwards, the sample was highly specialised and fell predominantly within a narrow age range and an upper CPA capability and mode range. Therefore, generalisability of the results is complicated, as the sample was made up of a restricted range of 527 managerial and professional staff members with only age, gender and race being considered as biographical variables. Care should thus be taken in interpreting the results, as the sample represented a narrow range, and hence population validity was limited (Johnson \& Christensen, 2012). Thirdly, the reported correlation coefficients between the first and second CPA assessment scores could also be deflated by inter-rater reliability, which has not been incorporated in the data analysis, thereby placing an upper limit on the correlation between these two data sets.

Future research should attempt to gain data via other means than the archival data used in this study. Future studies could also include a broader range of demographical variables and individuals from numerous demographic backgrounds and South Africa-based organisation types in order to enhance the generalisability of the research for the South African population. Assessing inter-rater reliability along with test-retest reliability could also be considered in future studies. Longitudinal studies should also consider the test-retest reliability of the CPA procedure as individuals mature over time.

\section{Conclusion}

Notwithstanding the limitations pointed out, the present study makes an important contribution to assessment practice in the South African context. In light of the paucity of recent research on $\mathrm{CPA}$, the value-add of the present findings lies in the validation of the test-retest reliability of the CPA procedure when applied in the South African employment equity context. It is apparent from the findings that the CPA procedure can be used with confidence as a tool for assessing current and potential levels of work decision-making capability in the selection and development of managerial and professional talent in the South African context.

\section{Acknowledgements Competing interests}

The authors declare that they have no financial or personal relationship(s) that may have inappropriately influenced them in writing this article. 


\section{Authors' contributions}

E.K. (University of South Africa) was the project leader. R.M.O. (University of South Africa) and M.C. (University of South Africa) wrote and edited the manuscript.

\section{References}

Ashton, L., Calitz, P., \& Solms, R. (2009).Wisdom @ work: From potential to performance and everything else. Randburg: Knowledge Resources.

Ashton, L., \& Kruger, E.H. (2008). Career path appreciation manual for practitioners. Bedfordview: Bioss Southern Africa.

Ashton, L., \& Kruger, E.H. (2010). Custodian workshop: Guide to using Bioss related technologies. (4th edn.). Bedfordview: Bioss Southern Africa.

Cascio, W.F., \& Aguinis, H. (2014). Applied psychology in human resource management (7th edn.). London: Pearson.

Comaroff, Y. (2012). Capacity for complexity, intelligence and personality. Unpublished master's research report, Department of Psychology, University of the Witwatersrand, Johannesburg, South Africa.

Converse, P.D., Pathak, J., DePaul-Haddock, A.M., Gotlib, T., \& Merbedone, M. (2012). Controlling your environment and yourself: Implications for career success. Journa of Vocational Behavior, 80, 148-159. http://dx.doi.org/10.1016/j.jvb.2011.07.003

Csíkszentmihályi, M. (1975). Beyond boredom and anxiety: Experiencing flow in work and play. San Francisco, CA: Jossey-Bass.

Csíkszentmihályi, M. (2003). Good business: Leadership, flow, and the making of meaning. New York, NY: Penguin Books.

Guion, R.M., \& Highhouse, S. (2006). Essentials of personnel assessment and selection London: Lawrence Erlbaum Associates.

Harry, N. (2014). Constructing a psychological coping profile for call centre agents. Unpublished doctoral thesis, Department of Industrial and Organisational Psychology, University of South Africa, Pretoria, South Africa.

Jaques, E. (1972). Equity in compensation. In H.L. Tosi, R.J. House, \& M.D. Dunnette (Eds.). Managerial motivation and compensation (pp. 190-206). Lansing, MI: MSU Business Studies.

Jaques, E. (1978). Levels of abstraction in logic and human action. London: Heinemann Educational.

Jaques, E. (1990). Creativity and work. Madison, CT: International University Press.

Jaques, E. (1996). The requisite organisation. (2nd edn.). Arlington, VA: Cason Hall.

Jaques, E., \& Cason, K. (1994). Human capability: A study of individual potential and its application. Arlington, VA: Cason Hall.

Jaques, E., \& Clement, S.D. (1994). Executive leadership: A practical guide to managing complexity. Arlington, VA: Cason Hall.

Johnson, B., \& Christensen, L. (2012). Educational research: Quantitative, qualitative, \& mixed approaches. (4th edn.). Thousand Oaks, CA: Sage

Kitching, J. (2005). The measurement outcome equivalence of the Career Path Appreciation (CPA) for employees from diverse cultural backgrounds. Unpublished master's dissertation, Department of Human Resource Management, University of Pretoria, Pretoria, South Africa.
Kruger, E.H. (2013). Assessing the accuracy of the growth in theoretical capability as predicted by Career Path Appreciation (CPA) 1 vs CPA 2. Unpublished master's dissertation, Department of Industrial and Organisational Psychology, University of South Africa, Pretoria, South Africa.

Lewis, P. (1993). Career Path Appreciation: Data reductions and analysis. Alexandria, VA: US ARI Technical Report.

Mauer, K.F. (1997). An evaluation of the selection procedures used by an organisation for the purpose of selecting BOP operators, supervisors, team leaders and process artisans, with comments on selected legal implications. Johannesburg: process artisans, with
Bioss Southern Africa.

Mauer, K.F. (2000). Psychological test use in South Africa. Pretoria: Department of Industrial Psychology, Unisa.

Mauer, K.F. (2002). The impact of retesting on assessment procedures - with special reference to the CPA. Bedfordview: Bioss Southern Africa.

Mauer, K.F. (2005). A summary of the statistical information of the Career Path Appreciation (CPA) interview. Bedfordview: Bioss Southern Africa.

Mauer, K.F. (2008). Career Path Appreciation: Consistency across repeated applications. London: Bioss International.

Nzama, L., De Beer, M., \& Visser, D. (2008). Predicting work performance through selection interview ratings and psychological assessment. South African Journa of Industrial Psychology, 34, 39-47.

O'Neil, D.A., \& Bilimoria, D. (2005). Women's career development phases: Idealism, endurance and reinvention. Career Development International, 10, 168-189. http://dx.doi.org/10.1108/13620430510598300

Percival, G., Crous, F., \& Schepers, J.M. (2003). New evidence of a relationship between capability and job complexity. South African Journal of Industria Psychology, 29(2), 60-71.

Schreuder, A.M.G., \& Coetzee, M. (2011). Careers: An organisational perspective. (4th edn.). Cape Town,: Juta.

SPSS Statistics for Windows version 21.0 [Computer software] (2012). Armonk, NY: IBM Corporation.

Stamp, G. (1981). Levels and types of managerial capability. Journal of Management Studies, 18, 1-21. http://dx.doi.org/10.1111/j.1467-6486.1981.tb00103.x

Stamp, G. (1988). Longitudinal research into methods of assessing managerial potential. Uxbridge, Middlesex: Bioss.

Stamp, G. (1989). The individual, the organisation and the path to mutual appreciation. Personnel Management, 21, 28-31.

Stamp, G. (1993). The essence of levels of work. Johannesburg: Bioss Southern Africa. http://dx.doi.org/10.1108/09556219310038846

Stamp, G., \& Retief, A. (1996). Towards a culture free identification of working capability: The career path appreciation. In J. Venter, H. de Beer, \& B. Tashe (Eds.), Towards culture-free identification of leadership potential (pp. 277-282). Johannesburg: Knowledge Resources.

Stamp, G., \& Stamp, C. (1993). Wellbeing at work: Aligning purposes, people, strategies, and structures. The International Journal of Career Management, 5 , $1-36$.

Super, D. (1990). A life-span, life-space approach to career development. In D. Brown, L. Brooks, \& Associates (Eds.), Career choice and development Applying contemporary theories to practice (pp. 197-261). San Francisco, CA Jossey-Bass. 